The pragmatic narrative of the Qur'anic discourse, the rhetoric of the argumentative and persuasion; Surat Al-Baqara and Taha as a case study

\section{Khadidja Merat}

Department of Language and Arabic Literature, University Mohamed Lamine

\author{
khadidjamerat@gmail.com
}

Dabbaghine Setif 2, Algeria

\begin{abstract}
Argumentative discourse occupies a large space in the Qur'an text in general and the two surat al-Baqara and Taha in particular, and this is evident through the multiplicity of topics they dealt with and the diversity of those addressing them. This is what led to the employment of many orbital mechanisms. Linguistic, rhetorical ... with the aim of attracting the attention of those addressed in order to comply and be convinced of what they were ordered, and for that this study came with the help of the pragmatic approach to shed light on the mechanisms of argumentative and persuasion in Surat Al-Baqara and Surat Taha, that is because their goal is to make the recipient party convinced of submission to God Almighty. Through the presentation of the verses of the argument and the dialogue that took place between the sender and the recipient, and the monitoring of verbal actions and argumentative links to achieve the strategy of persuasion within the large field of discourse strategies Which means that the accomplished speech is an ongoing planned speech, As the sender intends in his speech to employ an appropriate strategy that expresses his intention and achieves his goal, in the words of Abdul Hadi bin Dhafer Al-Shehri, which is a pragmatic strategy, which gets its name from the goal of the speech, and the act of persuasion and its guidance is always based on previous assumptions about the elements of the context, especially the addressee. The strategy for achieving the goals of the sender.
\end{abstract}

Keywords: argumentative, persuasion strategy, dialogue, context, discourse, pragmatic

Citation: Merat, Khadidja. Autumn \& Winter (2020-2021) "The pragmatic narrative of the Qur'anic discourse, the rhetoric of the argumentative and persuasion; Surat AlBaqara and Taha as a case study". Studies in Arabic Narratology, 2(3), 234-254. (In Arabic)

Studies in Arabic Narratology, Autumn \& Winter (2020-2021), Vol. 2, No.3, pp. 234-254

Received: March 2, 2021; Accepted: May 7, 2021

(C)Faculty of Literature \& Humanities, University of Kharazmi and Iranian Association of Arabic Language \& Literature. 


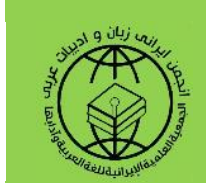

دراسات في السردانية العربية

الرقم الدولي الموحد للطباعة: • rTVT-VVE

الرقم الإلكتروني الدولي الموحد: IVIV-_IVq

تداولية الخطاب السردي القرآني و بلاغة الحجاج والإقناع؛ سورتا البقرة و طه

أنموذجا

khadidjamerat@gmail.com

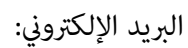

خديجة مرات

قسم اللغة العربية وآدابها، جامعة محمد لين دباغين، سطيف؟، الجزائر

الإحالة: مرات، خديجة. خريف وشتاء (•r.r-Y.Y.Y). تداولية الخطاب السردي القرآني وبلاغة الحجاج والإقناع؛ سورتا البقرة و طه أفموذجا. دراسات في السردانية العربية، ؟(ب)، عسب-

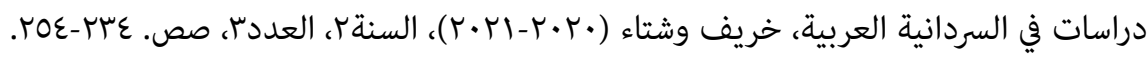

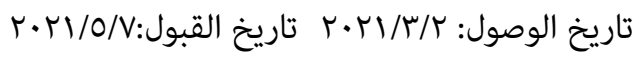

(ج) كلية الآداب والعلوم الإنسانية بجامعة الخوارزمي والجمعية العلمية الإيرانية للغة العربية

يشغل الخطاب الحجاجي حيّزا كبيرا في النص القرآني بشكل عام وسورتي البقرة

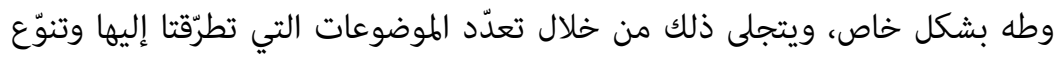


المخاطبين فيهما؛ هذا ما أدّى إلى توظيف كثير من الآليات الحجاجية: لغوية، وبلاغية... بقصد جذب انتباه المخاطبين من أجل الامتثال والاقتناع بما أُمروا به، ومن أجل ذلكن، جاءت هذه الدراسة معتمدة على منهج وصفي تحليلي وبالاستعانة باللقاربة التداولية لتسلّط الضوء على آليات الحجاج والإقناع في سورة البقرة وسورة طه؛ ذلك لأنّ غايتهما

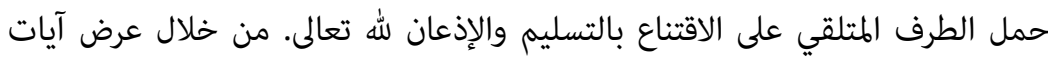
الحجاج والحوار التي دارت بين المرسل والمتلقي، ورصد الأفعال الكلامية والروابط الحجاجية لتحقيق استراتيجية الإقناع المنضوية ضمن الحقل الكبير المعروف باستراتيجيات الخطاب نتناول هذه القضايا اللسانية التي تعني أن الخطاب المنجز

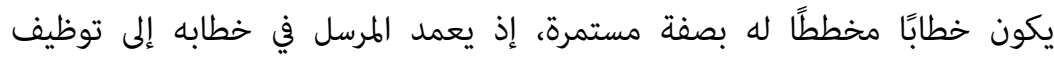
استراتيجية مناسبة تعبر عنمقصده وتحقق هدفه على حدّ تعبير عبد الهادي بن ظافر الشهري، وهي استراتيجية تداولية، تكتسب اسمها منهج الخطاب، ويبني فعل الإقناع وتوجيهه دومًا على افتراضات سابقة بشأن عناصر السياق خصوصًا المرسل إليه، وتستعمل هذه الاستراتيجية من أجل تحقيق أهداف المرسل.

الكلمات الدليلية: الحجاج، استراتيجية الإقناع، الحوار، السياق، الخطاب،

التداولية.

يعدّ الخطاب القرآني بنية تبليغية مؤسسة على آليات خطابية تواصلية قائمة على محاورة الآخر ومخاطبته. لذا كانت العملية التواصلية فيه مواكبة للتطوّر الحاصل لظروف الإنسان من بن أجل تحقيق التفاعل بين الأصل والفرع. وقد استخدم الخطاب القرآني من أجل ذلك استراتيجية الإقناع والحجاج لجذب واستقطاب اللناس نحو عقيدة الإسلام، وقد قَّّن الخطاب القرآني من التأثير في المتلقين وذلك لاعتماده على استراتيجيات وآليات لغوية ودلالية وتداولية تحاكي عقل المتلقي وأفكاره. لذا، فإنّ اللغة الحجاجية في الخطاب القرآني تشكّل بؤرة العملية التواصلية، وذلك للتأثير على المخاطبين وجعلهم يقتنعون بهذا الخطاب ويلتزمون به في معاملاتهم وسلوكياتهم، فالحجاج آلية 
تجسّد الخطاب الإقناعي، وتكمن أهميته فيما يتأكد من إقناعٍ لدى المتلقي عن طريق اللغة،

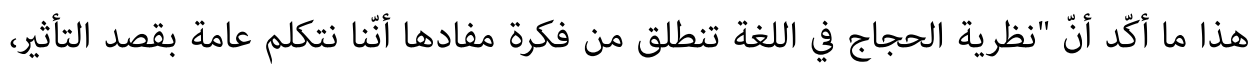
وأن الوظيفة الحجاجية للغة هي الحجاج، وأن المعنى ذو طبيعة حجاجية" (ظافرالشهري، (rV:

\section{منهج البحث وأهدافه}

جاءت هذه الدراسة معتمدة على منهج وصفي تحليلي وبالاستعانة باللقاربة التداولية لتسلّط الضوء على آليات الحجاج والإقناع في سورة البقرة وسورة طه؛ ذلك لأنّ غايتهما حمل مله الطرف المتلقي على الاقتناع بالتسليم والإذعان لله تعالى. أسئلة البحث يحاول هذا البحث الإجابة عن السؤالين التاليين: - ل - - ما أهم الأفعال الكلامية في سورتي البقرة وطه؟ - على ماذا تدل استخدام هذه الأفعال الكلامية في السورتين المذكورتين؟ خلفية البحث

لقد قت دراسة بعض السور القرآنية من مثل سورتي يوسف وسورة موسي (عليهما السلام)

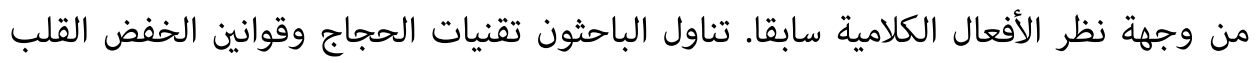
وغيرها في مثل هاتين السورتين ولكنه على أساس ما بحثنا، لم نجد بحثا يتناول الأفعال الكلامية وسبب استخدامها في سورتي البقرة وطه متزامنا. إلا أن البحث المتعلق بتومي عيسى (د.ت)

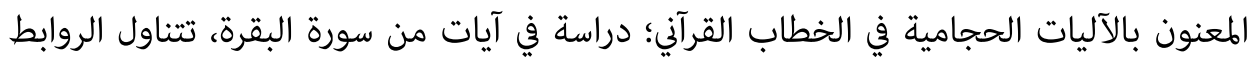
الحجامية من نوع العناصر النحوية والظروف مثل الواو والفاء ولاسيما وغيرها في خطاب بعض آيات السورة. أما درسنا بعض الأفعال العرضية والتمرسية في هذا البحث وتطرقنا إلى بعض الآليات البلاغية من غير الإستعارة في العينتين المطلوبتين. أوّلا - الضبط المفاهيمي والمصطلحي: 
لقد عرضت ديبوارا شيفرن ثلاثة تعريفات للخطاب، تمثّل في مجملها هذا التعدّد بل والتباين الناجم عن تعدّد مناهج الدراسات اللغوية مع نسبة كلّ تعريف إلى منهجه، لأنّ هذه التعاريف لاتعدو كونها تَثّل مناهج معيّنة. فقد ورد مفهوم الخطاب عند الباحثين بوصفه واحدا من ثلاثة: بوصفه أكبر من الجملة، أو بوصفه استعمال أي وحدة لغوية، أو بوصفه الملفوظ؛'إذ يتجسّد المنهج الشكلي في تعريف الخطاب الأوّل، وذلك بوصفه تلك الوحدة الأكبر من الجملة، فتتجه عناية الباحث إلى عناصر انسجامه، وترابطه، وتركيبه، ومعرفة علاقة وحداته بعضها ببعض، بل ومواءمةبعضها للبعض الآخر، وذلك على مستوى بنيته المنجزة (المصدر نفسه :^ب). ثم انتقلت شيفرن إلى الاتجاه الوظيفي، وهو تعريف الخطاب بوصفه استعمال اللغة كما هو عند بعض الباحثين، وذلك بتجاوز الخطاب وصفا شكليا، وعدم الاكتفاء بالوقوف عند بيان علاقة وحدات الخطاب ببعضها البعض وتحليلها. (المصدرنفسه). ثمّ أضافت ديبوارا شيفرن ضرورة الاعتناء بدور عناصر السياق، ومدى توظيفها في إنتاج الخطاب وفي تأويله؛ مثل دور العلاقة بين طرفي الخطاب، ودرجاتها الاجتماعية وطرقهما المعتادة في إنتاج خطاباتهم، فالتلفظ المتعدد لخطاب واحد، مثلا، يجسّد (الأنا) المتلفظة في تباينها الواقعي والاجتماعي مع المرسل إليه(الكصدرنفسه). وختمت شيفرن بالتعريف الثالث الذي هو تعريف الخطاب بوصفه ملفوظا، إذ يمثّل هذا التعريف نقطة التقاطع بين المنهجين السابقين، أي بين البنية والوظيفة، وقد يتخذ من الجملة

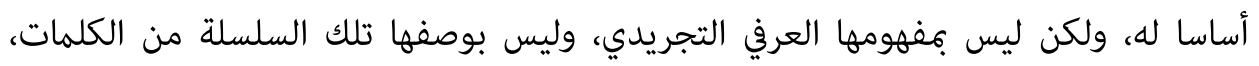

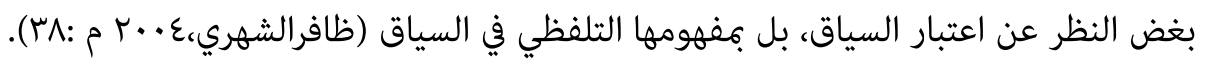
وقد عرّف الخطاب أيضا بأنّه:"كل منطوق به موجه إلى الغير بغرض إفهامه مقصودا مخصوصا مع تحقيق أهداف معيّنة ويقوم السياق على مجموعة من العناصر السياقية هي: المرسل والمرسل إليه والعناصر المشتركة، مثل العلاقة بين طرفي الخطاب، والمعرفة المشتركة والظروف الاجتماعية العامة بما تثيره من الافتراضات المسبقة و القيود التي تؤطر عملية التواصل (المصدر نفسه). 
اختلفت وجهات نظر الدارسين مفهوم الحجاج، فكلّ دارس عربيا كان أم غربيا ينظر إليه من زاويته الخاصة: البلاغية واللّسانية والفلسفية والأصولية، ممّا أدّى إلى تشعُب المفاهيم التي أثرت حقل اللسانيات عامة والحجاج خاصة. ومن بين هذه المفاهيمماحدده كلّ من بيرمان"Perlman"وتيتكا "tyteca" في موضوع الحجاج، وهو درس تقنيات الخطاب التي من شأنها أن تؤدي بالأذهان الى التسليم بما يعرض عليها من أطروحات، أو أن تزيد فيدرجة ذلك مهو

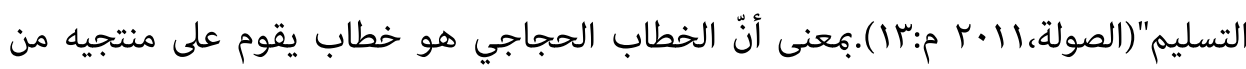
خلال حجاجهم المتماسك وفق ما تتطلبه الآليات الحجاجية المختلفة. وقد عرّف طه عبد الرحمن الحجاج بشيء من التداولية الجدلية حيث يقول: "إنّ الحجاج

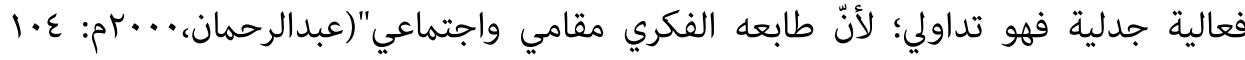
(بِعنى أنّ من شروط قيام الحجاج تداوليا وجود طرفي عملية التواصل وهما: المتكلم والمتلقي؛ وضرورة خضوعه للسياق المقامي و الاجتماعي، مع الاهتمام بانسجام الحوار، وذلك لتحقيق التأثير. فالحجاج هو الآلية الأبرز التي يستعمل المرسل اللغة فيها، وتتجسد عبرها استراتيجية الإقناع بحيث يعرّفه طه عبد الرحمن في موضع آخر بقوله:" كلّ منطوق به موجه إلى الغير لإفهامه

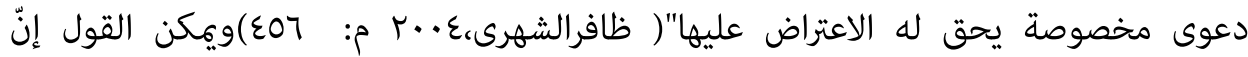
الحجاج حسب المعجم الفلسفي هو سلسلة من الأدّلة تُفضي إلى نتيجة واحدة، أو هو طريقة عرض الأدّلة وتقديمها، إذ يمكن اعتباراللغة بذاتها ذات بعد حجاجي في جميع مستوياتها: ويظهر ذلك في نظام بنيتها، لأنّ المتكلّم يستخدم الوحدات اللسانية، حسب ما يريد إبلاغه من أفكار، وبالقدر المقصود ويبني هذه الوحدات وفقا لأغراض التواصل المختلفة. ولذلك الدارسون بلاغة الحجاج وغايته، في أنّ المتكلّم ينتظر ممّن يوجه إليهم الخطاب حركة تنسجم مع المقاصد

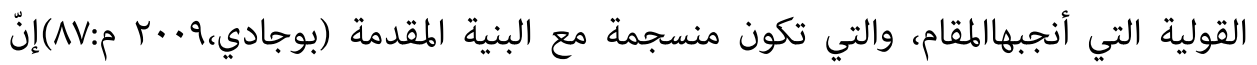
الحجاج بتعريف مختصر هو: طريقة عرض الحجج وتقديهها((المصدرنفسه:7 · ( ) أصناف الحجاج: يقسّم الحجاج إلى صنفين هما: الحجاج التوجيهي والحجاج التقويمي، وذلك باعتبار استحضار حجاج المرسل إليه من عدمه، سواء الحجاج السابق أو الحجاج المتوقع، فقد 
يكتفي المرسل بإنتاج خطابه دون تفكير فيما لدى المرسل إليه من حجج قد يواجهه بها، أو بأن يضع تلك الحجج المفترضة أو المتوقعة في حسبانه فتصبح أساسا يبني عليه خطابه (ظافر

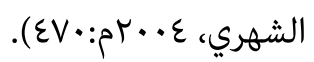

الحجاج التوجيهي: "المقصود بالحجاج التوجيهي هو إقامة الدليل على الدعوى بالبناء على فعل

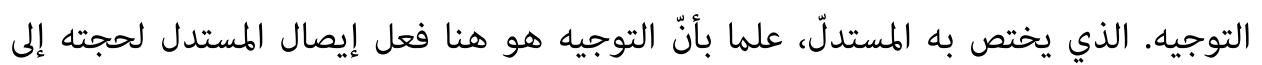
غيره؛ فقد ينشغل المستدل بأقواله من حيث إلقاؤه لها ولا ينشغل بنفس المقدار بتلقي المخاطَب لها ورد فعله عليها، فتجده يولي أقصى عنايته إلى قصوده وأفعاله المصاحبة لأقواله لهن الخاصّة، غير أنّ قصر اهتمامه على هذه القصود والأفعال الذاتية يفضي به إلى تناسي الجانب إنب العلاقي من الاستدلال، هذا الجانب الذي يصله باللخاطب ويجعل هذا الأخير متمتعا بحقّ إنى

$$
\text { الاعتراض." (المصدرنفسه). }
$$

الحجاج التقويمي: هو إثبات الدعوى بالاستناد إلى قدرة الطستدل على أن يجرّد من نفسه ذاتا ثانية ينزلها منزلة المعترض على دعواه؛ فهاهنا لايكتفي المستدل بالنظر في فعل إلقاء الحجّة إلى بلى المخاطَب، واقفا عند حدود ما يوجب عليه من ضوابط وما يقتضيه من شرائط، بل يتعدّى ذلك ملك

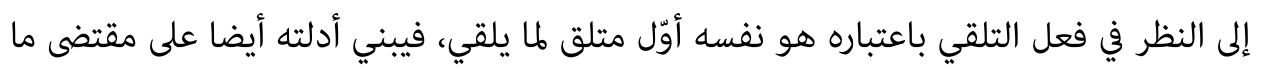
يتعين على المستدل له أن يقوم به، مستبقا استفساراته واعتراضاته ومستحضرا مختلف الأجوبة عليها ومستكشفا إمكانات تقبّلها واقتناع المخاطب بها، وهكذا فإنّ المستدل يتعاطى لتقويم دليله بإقامة حوار حقيقي بينه وبين نفسه، مراعيا فيه كل مستلزماته التخاطبية من قيود تواصليّة وحدود تعاملية، حتى وكأنه عين المستدل له في الاعتراض على نفسه." (المصدر نفسه:

يكن تقسيم آليات الحجاج إلى:

الأدوات اللغوية الصرفة؛ مثل ألفاظ التعليل، بما فيها الوصل السببي، والتركيب الشرطي، وكذلك الأفعال اللغوية، والحجاج بالتبادل، والوصف وتحصيل حاصل. الآليات البلاغية: مثل تقسيم الكلّ إلى أجزائه، والاستعارة، البديع، والتمثيل. 
الآليات شبه المنطقية: ويجسّدها السلم الحجاجي بأدواته وآلياته اللغوية؛ مثل الروابط

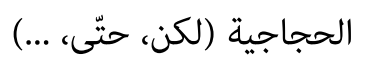

آليات الصيغ الصرفية: مثل التعدية بأفعل التفضيل والقياس وصيغ المبالغة. (المصدر نفسه:

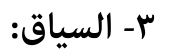

يضطلع السياق بأدوار كثيرة في التفاعل الخطابي، مثل تحديد قصد المرسل، ومرجع العلامات، ويطلق مصطلح السياق على مفهومين: السياق اللغوي وسياق التلفظ أو سياق الحال

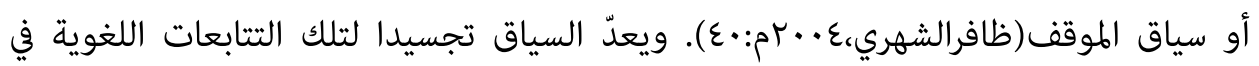
شكل الخطاب، من وحدات صوتية وصرفية، ومعجمية، ومابينها من ترتيب وعلاقات

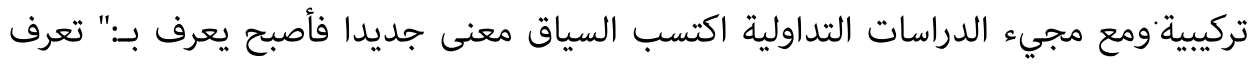
مجموعة الظروف التي تحفّ حدوث فعل التلفظ بموقف الكلام...وتسمّى هذه الظروف في بعض الأحيان بالسياق"((المصدرنفسه:•ع-(ع). ع- استراتيجية الإقناع: - 2 - 2

يرمي المرسل من خلال خطابه إقناع المرسل إليه بما يراه، أي "إحداث تغيير في الموقف التفاع الفكري أو العاطفي"ولتحقيق هذا الهدف استراتيجية تداولية تعرف باستراتيجية الإقناع، إذ تكتسب اسمها من هدف الخطاب وتختلف الاستراتيجيات التي تسهم في ذلك من ناحية العلاقة بين طرفي الخطاب أو من ناحية تجسيدها لشكل الخطاب اللغوي، كما تختلف الآليات والأدوات اللغوية، وذلك لاختلاف الحقول التي يمارس المرسل فيها الإقناع مثل: الحقل العلمي، أو الاجتماعي، أو السياسي.(المصدرنفسه:ععع). مسوغات استعمال استراتيجية الإقناع: هناك عدد من المسوغات التي ترجّح استعمال الإقناع، فممّا يرجّح استعمالها دون غيرها

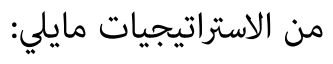

ا - أنّ تأثيرها التداولي في المرسل إليه أقوى، ونتاجها أثبت وديمومتها أبقى، لأنّها تنبع من حصول الاقتناع عند المرسل إليه غالبا، لا يشوبها فرض أو قوّة. 
r- تايزها عن الإستراتيجيات المتاحة الأخرى، مثل استراتيجيات الكراهية لفرض قبول القول

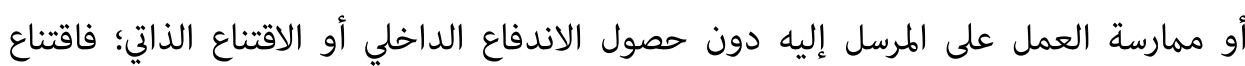
المرسل إليه هدف خطابي يسعى المرسل إلى تحقيقه في خطابه.

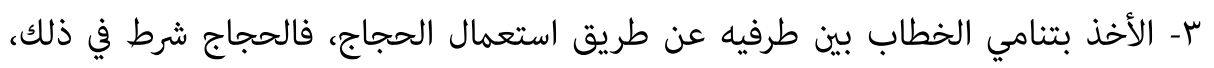
لأنّ شروط التداول اللغوي شرط الإقناعية. ع- الرغبة في تحصيل الإقناع؛ إذ يغدو هو الهدف الأعلى لكثير من أنواع الخطاب، خصوصا في العصر الحاضر، عندما يفضل المرسل استعمال استراتيجية الإقناع. 0- إبداع السلطة، فالإقناع سلطة عند المرسل في خطابه، ولكنها سلطة مقبولة إذا استطاعت أن تقنع المرسل إليه، إذ لا تحقق استراتيجية الإقناع نجاحها إلاّ عند التلسيم بمقتضاها، إما قولا

7- شمولية استراتيجية الإقناع، إذ تارس على جميع الأصعدة، فيمارسها الحاكم والفلاح

$$
\text { الصغير، وكبير القوم والطفل والمرأة، وكلّ ذلك بوعي منهم. }
$$

V- ماتحققه من نتائج تربوية، إذ تستعمل كثيرا في الدعوة، كما فعل رسول الله صلى الله عليه وسلم، مثلا عند إقناع الأعرابي الذي طلب الرخصة لارتكاب الزنا، فعن أبي أمامة ـ رضي الله عنه ـ قال: (إن فتى شابا أتى النبيَّ ـ صلى الله عليه وسلم ـ فقال: يا رسول الله، ائذن لي بالزنا!، فأقبل القوم عليه فزجروه، وقالوا: مه مه، فقال: ادنُ، فدنا منه قريبا، قال: فجلس، قال: أتحبه لأمك؟

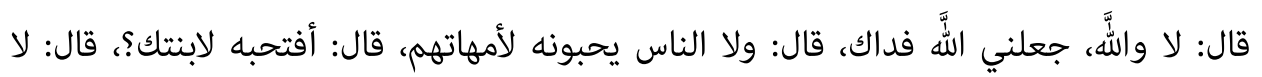

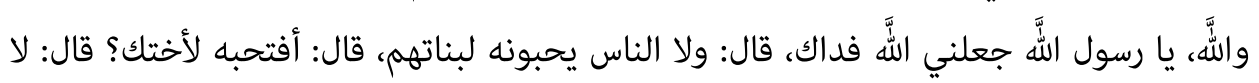
واللَّ، جعلني اللَّ فداك، قال: ولا الناس يحبونه لأخواتهم، قال: أفتحبه لعمتك؟ قال: لا واللَّه، لهان جعلني اللَّ فداك، قال: ولا الناس يحبونه لعماتهم، قال أفتحبه لخالتك؟ قال: لا واللَّ جعلني اللَّه فداك، قال: ولا الناس يحبونه لخالاتهم قال: فوضع يده عليه وقال: اللَّهمّ اغفر ذنبه وطهر قلبه، وحَصِّنْ فُرَجه، فلم يكن بعد ذلك الفتى يلتفت إلى شيء) رواه أحمد . وفي رواية أخرى: وقال: (اللهم طهر قلبه، واغفر ذنبه، وحَصِّنْ فْرجَه، فلم يكن شيء أبغض 
1- استباق عدم تسليم المرسل إليه بنتائج المرسل أو دعواه. 9- خشية سوء تأويل الخطاب.

•ا- عدم الاتفاق حول قيمة معينة، أو التسليم من أحد طرفي الخطاب للآخر.

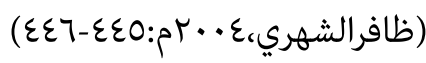

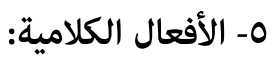

وهي الفكرة الأولى التي نشأت منها اللسانيات التداولية ومن أهمّمراجعها، بل يمكن التأريخ منها للتداولية؛ حيث ارتبطت اللغة بإنجازها الفعلي في الواقع، و"تسمية اقترحت في سنوات الستينيات من أوستين. استأنفت من طرف (سورل)، قبل أن تكون مقبولة من طرف كلّ

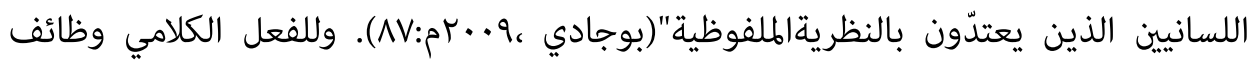
تداولية مرتبطة بقصد المخاطب، من أهمها "وظيفته الحجاجية" التي تزيد من فاعليته

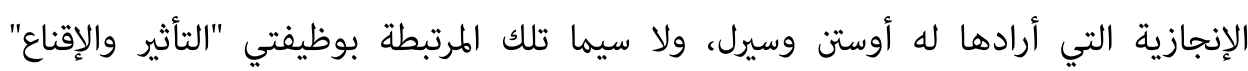

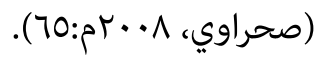

وحسب المتفق عليه فإنّ" فعل الكلام يعني لغة ما أو التحدث بما يعني تحقق أفعال لغوية"(بوقرة،7 +. بم:791).بحيث يستعمل المخاطب الفعل الكلامي المباشر عندما يولي عنايته لتبليغ قصده وتحقيق هدفه الخطابي ورغبته في أن يكلف المتلقي بعمل ما، أو يوجهه لمصلحته من جهة، وإبعاده عن الضرر من جهة أخرى، أو توجيهه لفعل مستقبلي معين، ويفتر أن يتوجه المخاطب بخطابه إلى التكثير من فائدة المتلقي، فيستعمل هذه الاستراتيجيات في شكلها الأكثر

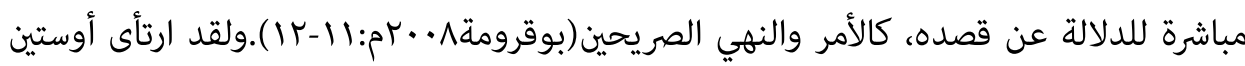
أن يصنف الأعمال التي ينجزها إلى خمسة أقسام استنادا إلى قوتها الإنجازية وهي: (بوجادي،

. (qV:5) ..

$$
\text { *الحكمية: (الإقرارية) حكم، وعد، وصف. }
$$

×الأفعال التمرّسية: وتعني إصدار قرار لصالح أو ضد...أمر، قاد، طلب. tأفعال التكليف: (الوعدية): تلزم المتكلم: وعد، تمنّى، التزم بعقد..

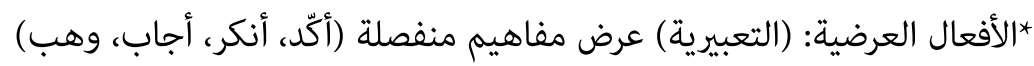


*أفعال السلوكات: (الإخباريات): ردود أفعال، تعبيرات تجاه السلوك، اعتذر، هنأ، رحّب... أمّا سورل فإنّه أوّل من أوضح فكرة أوستين وشرحها أكثر بتقديمه شروط إنجاز كل فعل، إلى جانب بيانه شروط تحوّل فعل من حال إلى حال أخرى، وآليات ذلك، وتوضيح خطوات استنتاج الفعل المقصود، وقد قدّم سورل أيضا الأفعال الكلامية وميّز بين أربعة أقسام: لتهرل

$$
\begin{aligned}
& \text { فعل التلفظ (الصوتي والتركيبي) } \\
& \text { الفعل القضوي (الإحالي والجملي) } \\
& \text { الفعل الإنجازي (على نحو ما فعل أوستين) } \\
& \text { الفعل التأثيري (على نحو ما فعل أوستين) (المصدرنفسه:^\). } \\
& \text { وسرعان ما اقترح خمسة أصناف لها وهي: }
\end{aligned}
$$

*الأخبار: تبلغ خبرا، وهي قتثيل للواقع، وتسمّى أيضا: التأكيدات، الأفعال الحكمية. *الأوامر: تحث المخاطب على فعل ما. *الالتزامية: (أفعال التعهّد) وهي أفعال التكليف عند أوستين، حين يلتزم المتكلم بفعل شيء

* التصريحات: وهي الأفعال التمرّسية عند أوستين، وتعبّر عن حالة معينة، مع شروط

$$
\text { صدقها. }
$$

(الإنجازيات: "الإدلاءات": تكون حين التلفظ ذاته. (المصدرنفسه:99).

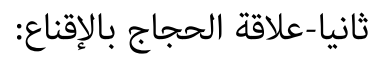
يؤكد بيرمان وزميله أنّ الغرض التداولي من الحجاج هو تحصيل الإقناع، حيث يقول: "إذعان

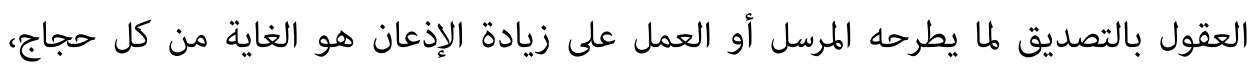
فأنجع حجة هي تلك التي تنجح في تقوية حدة الإذعان عند منيسمعها، وبطريقة تدفعه إلى المبادرة سواء بالإقدام على العمل أو الإحجام عنه، أو هي على الأقل ما تحقق الرغبة عند المرسل

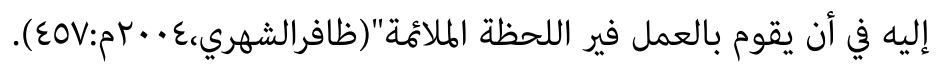
أولى هذا التعريف الإقناع مكانته، بأن جعل منه محور العملية الحجاجية، كما اعتبره أثرا مستقبليا يتحقق بعد التلفظ بالخطاب، وبهذا فإنّ دور الحجاج يقف عندهدف تحقيق الإقناع. 
وهذا الحذّ هو ما يمنحه صلاحيته لاستعماله آلية في السياقات المتنوعة مثل: الدعوة إلى الله وطلب الحقوق ... هذا ولقد بيّن الله تعالى في الخطاب القرآني في أكثر من موضع دور الحجة في الإقناع وبطرق مختلفة، أي بحسب قدرات الناس العقلية والعاطفية، فمنهم من يقنع بالفكرة عن طريق استهواء العاطفة وايقاظ الشعور، فيهتدي إلى المعرفة وإلى الحكم عن طريق تأمل باطني فيالحجج، ومنهم من لا يذعن لغير البرهان المباشر، ويستخدم الاستدلال المنطقي كالقياس والتمثيل والاستقراء، ومنهم من يقنع - كما يقول سيد قطب - "بعالم حي منتزع من عالم الأحياء لا ألوان مجردة، وخطوط تصوير تقاس الأبعاد فيه والمسافات بالمشاعروالوجدانيات، فالمعاني ترتسم وهي تتفاعل في نفوس آدمية حية، أو في مشاهد من الطبيعةتخلع على

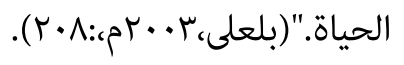

\section{ثالثا-الأفعال الكلامية في سورة البقرة:}

تضمنت سورة البقرة مجموعة من الأفعال الكلامية ، سيتّم استخراج بعض منها فيما سيأتي: قال تعالى:"إذ قال ربّك للملائكة إنّي جاعل في الأرض خليفة قالوا أتجعل فيها من يُفسد فيها ويسفك الدماء ونحن نسبّح بحمدك ونقدّس لك قال إنّي أعلم ما لا تعلمون" سورة البقرة الآية·باجاءت الآية هاهنا في سياق الإخبار، بحيث يدور فعل هذه الآيات حول معنى التعجّب والتعجيز، فالملائكة أصابها الذهول لمن سيستخلف لعمارة الأرض وإصلاحها من يفسد فيها

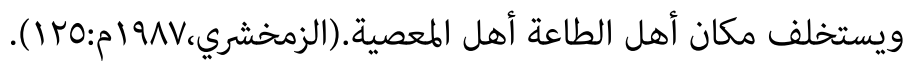

ويرى الألوسي أنّ هده الآية يتضمن الفعل الكلّي فيها مجموعة من الأفعال الكلامية هي: الإخبار والتقرير والتأكيد والتنويه، والتعجيز والاعتراف، والعطف، و(إذ) من عطف القصة على القصة، وفي كلّ تعداد النعمة، مع أنّ الأوّل تحقيق للفضل، وهذا اعتراف به". (الالوسي، 0 م. بم:

وفي قوله تعالى:"وعلّم آدم الأسماء كلّها ثمّ عرضهم على الملائكة فقال أنبئوني بأسماء هؤلاء،

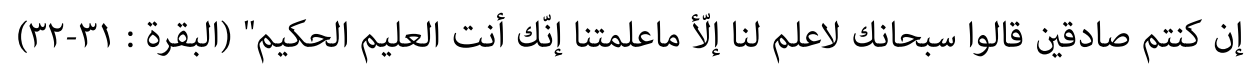
احتوت الآيتان الكريمتان على مجموعة من الأفعال الكلامية، بحيث ورد الإخبار بسياق التعجيز والتنويه في الفعل "أنبئوني" وذلك لإظهار عجز الملائكة وقصورهم عن رتبة الخلافة، أمّا 
ورود "إن الشرطية"فذلك توكيد ملا نبهه الله تعالى عليهم من القصور والعجز،وقد اعترف الملائكة بعجزهم في قوله تعالى" قالوا سبحانك لاعلم لنا..." وفي قوله تعالى:” وإذ واعدنا موسى أربعين ليلة ثم اتخذتم العجل من بعده وأنتم ظالكون ثم عفونا عنكم من بعد ذلك لعلكم تشكرون (Or) وإذ آتينا موسى الكتاب والفرقان لعلكم تهتدون (ساه) وإذ قال موسى لقومه يا قوم إنكم ظلمتم أنفسكم باتخاذكم العجل فتوبوا إلى بارئكم فاقتلوا أنفسكم ذلكم خير لكم عند بارئكم فتاب عليكم إنه هو التواب الرحيم (ع)

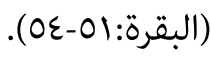

تتضمن هذه الآيات الكريمات مجموعة من الأفعال الكلامية من قبيل الإخبار، التذكير، الامتنان الذم، الترجي، هذا ويعدّ فعل الذمّ هو الفعل الكلامي الجامع وهذه الأخبار يراد بها التذكير وذّم بني إسرائيل لأنّهم عبدوا العجل واتخذوه إلها، ويتضمن الفعل معنى الترجي"لعلّكم" ومعناه لتكونوا على رجاء الشكر لله عز وجل ونعمه فينصرف الرجاء

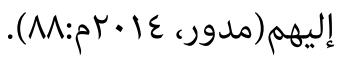
وفي قوله تعالى: "(إذ قال موسى لقومه ياقوم إنّك مظلمتم أنفسكم باتخاذكم العجل فتوبوا

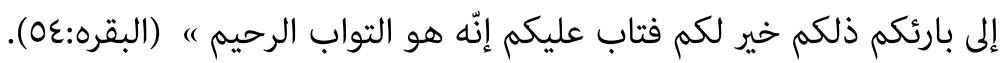
في الآية الكريمة الإخبارية ورد الفعل الكلامي دالا على الحثّ والتحريض على التوبة، في حين تراوحت الأفعال الكلامية الصغرى بين التحنن، التأكيد ، الإخبار، النداء، التنبيه...حيث استُهل الخطاب القرآني بنداء موسى لقومه وغرضه التحنّن عليهم، وذلك ليبيّن لهم أنه جزء منهم وأنهم جزء منه حتى يقنعهم بالإقبال على التوبة. وفي قوله تعالى:" وإذ قلنا ادخلوا هذه القرية فكلوا منها حيث شئتم رغدا وادخلوا الباب سجدّا وقولوا حطّة نغفر لكم خطاياكم وسنزيد المحسنين (0/) فبدّل الذين ظلموا قولا غير الذي قيل لهم فأنزلنا على الذين ظلموا رجزا من السماء بما كانوا يفسقون (09)” (البقرة:0^-

الأمر في الآية بالدخول بعد التيه هو أمر إباحة على وجه الإقامة والسكنى، فالأمر في الفعل "كلوا" يراد به حل جميع مواضعها أو الإذن بنقل حاصلها إلى أي موضع شاءوا، وتدّل لفظة 
"رغدا" على أنهم مرخصون بالأكل منها، ويحتمل أن يكون وعدا لهم بكثرة المحصولات(المصدرنفسه :19)وفي الفعل "وقولوا حطة نغفر لكم خطاياكم" فعل أمر تضمن فعلا كلاميا غير مباشر هو الوعد بالغفران، والإخبار في قوله تعالى:"وسنزيد المحسنين"يتضمن فعلا كلاميا غير مباشر هو وعد بالزيادة والإخبار في "فبدّل" يتضمن معنى الذم بسبب التبديل وإفا فعلوا ذلك استهزاء بما قيل لهم. وفي قوله تعالى: "ثم قست قلوبكم من بعد ذلك فهي كالحجارة أو أشدّ قسوة وإنّ من

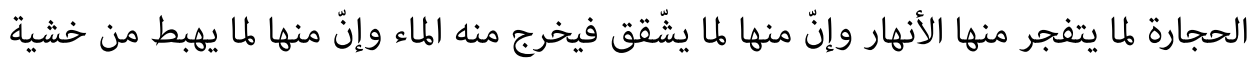
الله وما الله بغافل عمّا تعملونعV أفتطمعون أن يؤمنوا لكم وقد كان فريق منهم يسمعون كلام الله ثم يحرفونه من بعد ماعقلوه وهم يعلمونV0 وإذا لقوا الذين آمنوا قالوا أمنا وإذا خلا

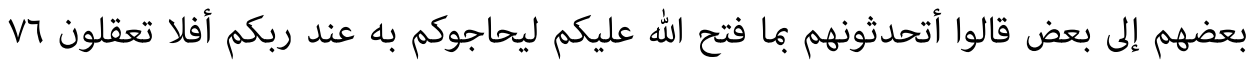

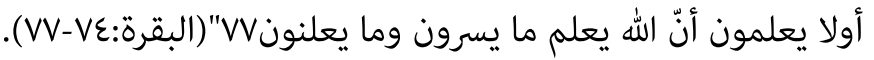
إنّ الخطاب هاهنا موجه إلى اليهود وقد وصفهم بالقاسية قلوبهم وأخبر عن كل قبائحهم وصفاتهم الذميمة مستبعدا الطمع في إيمانهم والأفعال الكلامية المستعملة هاهنا للتبليغ عنهم هي: الإخبار للتعبير عن المبالغة في قسوة قلوبهم، وقد استعمل في ذلك صيغة المبالغة "أشدّ"قسوة، وهنا نجد التشبيه قائم بين قلوب اليهود والحجارة والمقارنة بينهما أن قلوبهم لاتلين أبدا، في حين يمكن للحجارة أن تتأثر وتنفعل، وهنا يكمن الفعل الإنجازي غير المباشر "الذم" الذي تلاه مباشرة فعل الوعيد في قوله: "ومالله بغافل عمّا تعملون" الذي ورد بصيغة النفي للدلالة على أنّ الله بالمرصاد لهؤلاء القساة ولاتخفى القوة الحجاجية للفعل الكلامي المتعلق بكعاني الذمّ والوعيد، حين استعمل حجة التمثيل "فهي كالحجارة" وفي زيادة التوضيح فقد توجه بالخطاب إلى المؤمنين بقوله:"أفتطمعون" والططموع في إيمانهم هم اليهود، والفعل

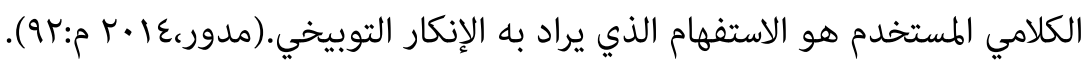
ويستمر الخطاب القرآني في كشف أخلاق وقبائح اليهود باستعمال مجموعة من الأفعال اللغوية الضمنية: كالعتاب والتوبيخ، الذي دل عليه الإخبار في قوله تعالى:"وإذا لقوا الذين آمنوا قالوا أمنّا" وقوله "ليحاجّوكم به" وذلك لتأكيد النكيروتشديد التوبيخ عليهم. 
رابعا-حجاج سيدنا موسى مع فرعون:

ورد الحجاج في الخطاب القرآني في مواقف عديدة، وتعدّ سورة "طه" من بين السور التي اعتمدت على استراتيجية الحجاج في مواقف عديدة، كالحجاج بين سيّدنا موسى مع الله تعالى وحجاجه مع فرعون، وقد اخترت بعض النماذج على سبيل التوضيح والتمثيل. يعرّف الحجاج على أنّه "العلاقة الدلالية التي تربط بين الأقوال في الخطاب وتنتج عن عمل المحاجّة ولكنّ هذا العمل محكوم بقيود لغويّة، فلا بدّ أن تتوفر في الحجّة ق ا (القول الأوّل للحجاج) شروط محددة حتى تؤدي إلى قץ (القول الثاني للحجاج) لذلك فإنّ الحجاج مسجّل في بنية اللغة ذاتها وليس مرتبطا بالمحتوى الخيري للأقوال ولا بمعطيات بلاغية مقامية"(المبخوت: 199ام :•7r-ا7r) وقد أثارت الرسالة التي نزل بها أنبياء الله ثورة في نفوس أقوامهم وملوكهم، ومن بينها الرسالة التي جاء بها سيدنا موسى إلى فرعون وأخبره أنه رسول الله مما جعله يعلن الحرب عليه وزرع الخصومة بينهما في كل لقاءاتهما، وكان أوّل لقاء جمعهما داخل قصر فرعون، وقد تطرّق الخطاب القرآني إلى الحوار والحجاج الذي دار بينهما أمام الجماهير، أمّا اللقاء الثاني فكان يوم الزّينة وقد وصفه القرآن بيوم جمع الناس ليقات يوم معلوم، وكان قد حضر جمع غفير من السحرة من أجل التحدّي، وقد اعتمد كلّ طرف طريقته لإضعاف حجج الآخر (زموش:

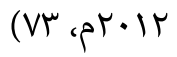

وتعدّ معرفة المخاطَب الذي يوّجه إليه الخطاب سببا في إنجاح العملية التخاطبية وللعملية الإقناعية، وفي هذا السياق يعرف سيدنا موسى المخاطَب جيّدا أو بعبارة أخرى يعرف سيدنا موسى فرعون جيّدا لأنه تربى في بيته لذا لم يجد استراتيجية للتعامل معه ومحاججته دون تردد، نظرا لحجم الرسالة التي كلّفه الله بها، وفي هذا المقام يقول الله تعالى على لسان سيّدنا موسى:» ربّ اشرح لي صدري (ro) ويسّر لي أمري (T) واحلل عقدة من لساني (YV) يفقهوا قولي(r^) واجعل لي وزيرا من أهلي (rq) هارون أخي (•r) اشدد به أزري(اس) وأشركه في أمري

. وقد استجاب الله تعالى لطلب سيّدنا موسى، بأن أرسل معه أخاه هارون وهداهما السبيل الواجب اتباعه من أجل النصر على فرعون، وهدّأ من روعهما بقوله تعالى:» قال لا تخافا إنني 
معكما أسمع وأرى《 وكان السبيل الذي وجههما الله إليه هو قوله تعالى" فقولا له قولا ليّنا لعلّه يتذكر أو يخشى" (طه:عع) وكذلك قوله تعالى (اتياه فَقولا إِنا رسولَا رَّبك فَاََرسلْ معنا بني إِسرائيل

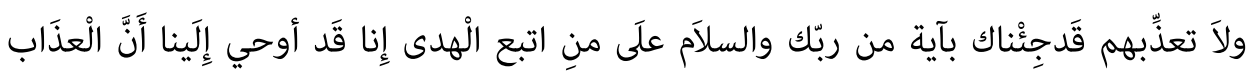

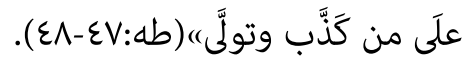

والقول الّلين في حد ذاته آلية تساعد في التقرب من الخصم وترغيبه، من أجل قبول القضية

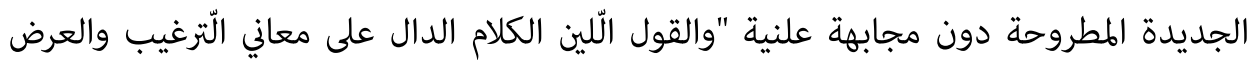

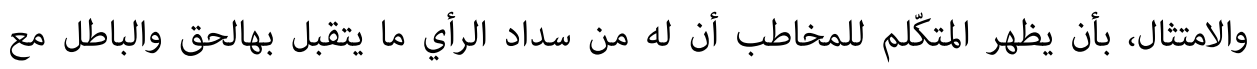
تجّنب أن يشتمل الكلام على تسفيه رأي المخاطب وتجهيله. فشبه الكلام المشتمل على المعاني الحسنة بالشيء اللين"(المرجع نفسه:VI).

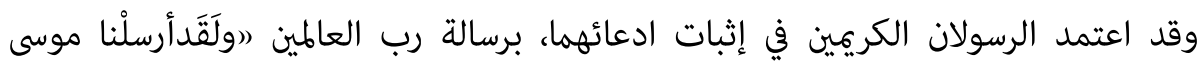

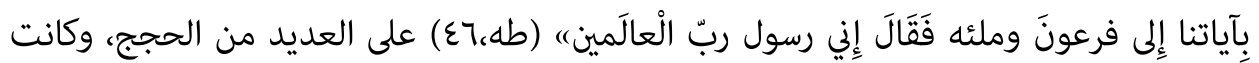
في البداية حججا قولية مقنعة تنفيذا لأوامر العليم الخبير. هذا وقد حاول سيّدنا موسى عليه السلام إشراك الجمهور الحاضر، وذلك بتوجيه الخطاب إليهم أيضا بعدما كان في البداية يخصّ به فرعون وحده. فبعد أن كان يحدّد المخاطب بفرعون دون غيره بقوله(ربك) باعتماد ضمير الخطاب الفردي، أصبح يقول إن (كنتم) (ربكم) (آبائكم) وغيرها الدّالة على توجيه الكلام لجميع الحضور (المرجع نفسه:Vا). كقوله تعالى: (الذي جعلَ

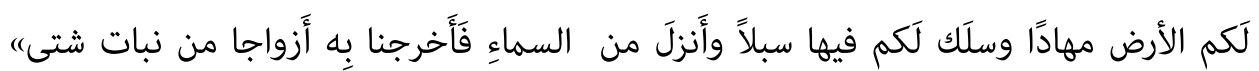
(이 (or)

أمّا عن فرعون؛ فقد اعتمد في البداية إستراتيجية سيدنا موسى عليه السلام نفسها؛ والتي اعتمدها في تبليغه أمر الرسالة، على أن ذلك لا يدل على أنه استجاب للأمر ودخل في الموضوع بالطريقة التي كان سيّدنا موسى مع أخيه هارون عليهما السلام يرومانها، فقد كان فرعون الطاغية مستعدا أن يضرب عرض الحائط، كل دعوة تأتيه من أي كان في سبيل الحفاظ على

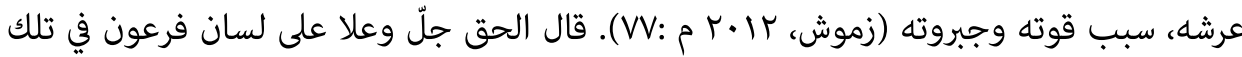
اللحظات: (رقَالَ فَمن ربكما يا موسى) (طه: وع). 
حيث عمد فرعون إلى اعتماد الإستراتيجية التلفظية نفسها أضاف الرب إلى ضمير موسى

$$
\text { وهارون في قوله(ربّكما) وفي هذا رد ضمني برفض إلى الدعوة. }
$$

وبعدما أقام سيّدنا موسى الحجة على فرعون، لجأ فرعون إلى الحجاج المغالط، لكون المغالطة شكل من أشكال الحجاج، تتجلى فيه المفارقات التي يمكن أن تسجّل بين أقوال الشخص وأفعاله، فبعدما أظهر النبي موسى عليه السلام لفرعون مأيّده الله به من الحجج والبينات والطعجزات، كان متوقعا أن يتنازل فرعون عن دعواه واتهامه، وينهي النزاع، غير أن فرعون غيّر من من من استراتيجيته، بحيث لجأ إلى مغالطة قومه بقوله: (رقال أجئتنا لتخرجنا من أرضنا بسحرك ياموسى فئي فلنأتينك بسحر مثله فاجعل بيننا وبينك موعدا لا نخلفه نحن ولا أنت مكانا سوى" (OV) (طه:ON-OV) (أمنا حاول فرعون إيهام سيدنا موسى أنه محاط بقومه وأنهم إلى جانبه من ناحية ومن ناحية أخرى يوهم قومه أنه حريص عليهم ويخاف عليهم من موسى وماجاء به وذلك في قوله تعالى:» وقال فرعون ذروني أقتل موسى وليدع ربّه إنّيّ أخاف أن يبدّل دينكم وأن يُظهر في فئي الأرض الفساد « ( طه :TY). وعليه، فإنّ توظيف قصة سيّدنا موسى مع فرعون ورد لغاية حجاجية، بحيث اعتمد كلّ

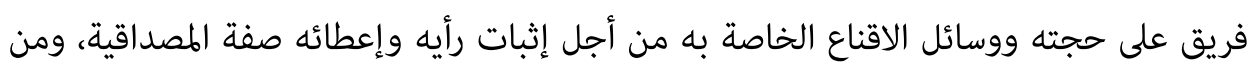
هنا يتبين أن السرد في الخطاب القرآني قائم على آليات المقاربة التداولية كاستعمال الأفعال الكلامية وماتضمنته من قوى ضمنية وإنجازية، إضافة إلى آلية الحجاج والإقناع، ذلك أن الهدف من القرآن الكريم هو التسليم لأوامر الله والإذعان لها، ولا يتاتى ذلك إلا بالحجج والبراهين التي تجعل المتلقي يقتنع بما يسمعه، وهذا ماكان حاضرا وبقوة في سورتي البقرة وطه.

النتائج: بعد عرض بعض النماذج من الأفعال الكلامية والحجاج في سورتي البقرة وطه نصل إلى أهمّ النتائج وهي: - n

-لقد توفرت في القرآن الكريم مجموعة من الخصائص التي جعلت منه خطابا حجاجيا، إضافة إلى أن القرآن خطاب، والخطاب يحمل في طياته الحجاج الذي يقوم على الإقناع والتأثير. 
-لقد أثبتت الدراسات التداولية أنّ القرآن الكريم كتاب حجاجي بامتياز؛ ذلك كونه جاء بهدف تغيير الأخلاق والمبادئ التي كانت عليها الأمم.

-ميثّل السردالقرآني آلية حجاجية، بحيث يصنّف ورود قصة سيدنا موسى مع فرعون لغاية حجاجية. -وردت الأفعال الكلامية غير المباشرة في الخطاب القرآني بكثرة وقد استعملت القوة الإنجازية الضمنية في سورة البقرة أكثر من القوة الإنجازية الصريحة وكلّ ذلك مردّه إلى ثقة المرسل في الكفاية التداولية للمتلقي وفي كفاءته على التأويل والفهم. -جاءت الأفعال الإخبارية دالة على قوة إنجازية مباشرة ومستلزمة، تتمثل القوة المباشرة في الوصف والإخبار والتقرير وتتمثل القوة المستلزمة في النفي والإثبات والتأكيد. إنّ توظيف قصة سيّدنا موسى مع فرعون ورد لغاية حجاجية، بحيث اعتمد كلّ فريق على حجته ووسائل الاقناع الخاصة به من أجل إثبات رأيه وإعطائه صفة المصداقية، ومن هنا يتبين أن السرد في الخطاب القرآني قائم على آليات المقاربة التداولية كاستعمال الأفعال الكلامية وماتضمنته من قوى ضمنية وإنجازية، إضافة إلى آلية الحجاج والإقناع، ذلك أن الهدف من القرآن الكريم هو التسليم لأوامر الله والإذعان لها، ولا يتاتى ذلك إلا بالحجج والبراهين التهائ التيه تجعل المتلقي يقتنع بما يسمعه، وهذا ماكان حاضرا وبقوة في سورتي البقرة وطه.

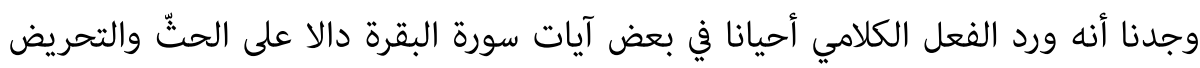

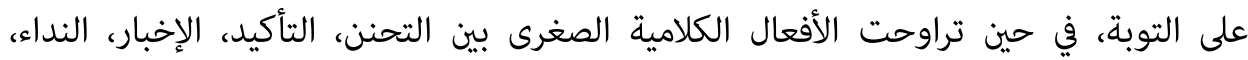
التنبيه...حيث استُهل الخطاب القرآني بنداء موسى لقومه وغرضه التحنّن عليهم، وذلك ليبيّن لهم أنه جزء منهم وأنهم جزء منه حتى يقنعهم بالإقبال على التوبة.

المصادر والمراجع

الألوسي، أبو الفضل شهاب الدّين محمود(0.. بم)، روح المعاني في تفسير القرآن الكريم، تح:

$$
\text { سيد عمران، دار الحديث: القاهرة. }
$$

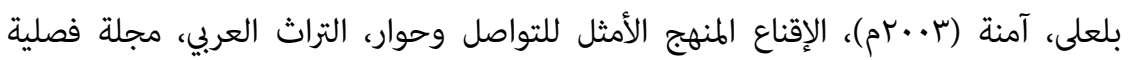
محكمة تصدر عن اتحاد الكتاب العرب بدمشق، العددهی. 
بوقرومة، حكيمة (^ • بم)، دراسة الأفعال الكلامية في القرآن الكريم، مقاربة تداولية، مجلة الخطاب، جامعة تيزي وزو، العدد؟.

بوجادي، خليفة(9..بم) في اللسانيات التداولية، مع محاولة تأصيلية في الدرس العربي القديم، بيت الحكمة، العلمة، الجزائر، طا.

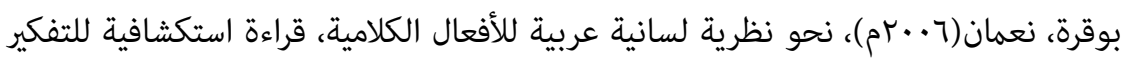
التداولي في المدونة اللسانية التراثية، مجلة اللغة والأدب، جامعة الجزائر، العدد IV لونائ.

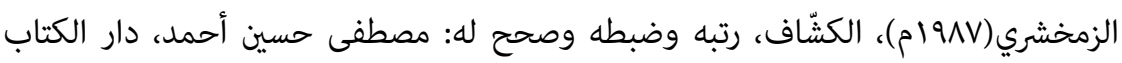

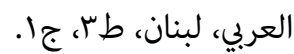
زموش، كهينة (r إب م) حجاج موسى عليه السلام في النص القرآني، دراسة تداولية، رسالة ماجستير، جامعة مولود معمري تيزي وزو.

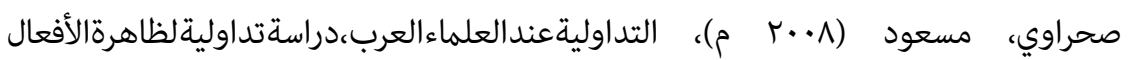
الكلاميةفي التراث العربي اللساني،دارالتنوير،الجزائر،طا. صولة، عبد الله (11 •rم)، في نظريةالحجاج دراسةوتطبيقات، ميكلياني، تونس، طا.

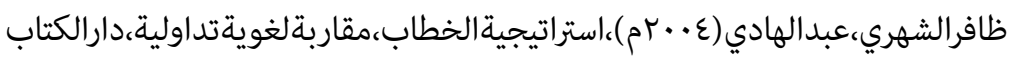

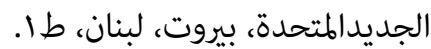
عبد الرحمان، طه(...rم)، في أصول الحوار، وتجديدعلم الكلام، المركزالثقافي العربي، بينان

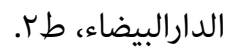
المبخوت، شكري، (199/م) نظرية الحجاج في اللغة، منشورات كلية الآداب، جامعة منوبة، تونس. مدور، محمد(عا.بrم)، الأفعال الكلامية في القرآن الكريم، سورة البقرة دراسة تداولية، أطروحة دكتوراه في علوم اللسان، جامعة الحاج لخضر، باتنة، الجزائر.

\section{Refrences}

- Al-Alousi, Abu Al-Fadl Shehab Al-Din Mahmoud (2005) The Spirit of Meanings in Interpretation of the Holy Quran, Under: Syed Imran, Dar Al-Hadith: Cairo. 
- Bel Ali Amna (2003), Persuasion, the Best Approach for Communication and Dialogue, Arab Heritage, a quarterly refereed journal; issued by the Arab Writers Union in Damascus, Issue 89.

- Boukroumeh, Hakima (2008), Study of verbal verbs in the Noble Qur'an, a deliberative approach, Al-Khattab Journal, Tizi Ouzou University, No. 3

- Boujadi, Caliph (2009) in deliberative linguistics, with an original attempt in the old Arabic lesson, House of Wisdom, El Alamah, Algeria, ed1.

- Bougherra, Nouman (2006), an Arabic linguistic theory of verbal verbs, an exploratory reading of deliberative thinking in the heritage linguistic code, Journal of Language and Literature, University of Algeria, Issue 17

- Al-Zamakhshari (1987), The Scout, Rank, Adjust, and Correct Him: Mustafa Hussein Ahmad, Dar Al-Kitaab Al-Arabi, Lebanon, ed. 3, c1.

- Zamoush, Kahinah (2012) Hajjaj Musaee, peace be upon him, in the Qur'an text, pragmatic study, Master's thesis, University of Mouloud Mamari Tizi Ouzou.

- Sahrawi, Masoud (2008), The deliberative study of the Arab scholars, a deliberative study of the phenomenon of verbal verbs in the Arab linguistic heritage, Dar Al-Tanweer, Algeria, i 1.

- Soula, Abdullah (2011), The Theory of Al-Hajjaj, a Study and Applications, Micheliani, Tunis, 1st Edition.

- Dhafer Al-Shehri, Abdel-Hadi (2004), The Discourse Strategy, a pragmatic linguistic approach, The United Al-Kitab Al-Jadid House, Beirut, Lebanon, 1 ed.

- Abd al-Rahman, Taha (2000), in the fundamentals of dialogue and the renewal of the science of speech, the Arab Cultural Center, Casablanca, 2nd floor.

- Al-Mabkhout, Shukry, (1998) The Theory of Pilgrims in Language, Publications of the Faculty of Arts, Manouba University, Tunisia.

- Medawar, Muhammad (2014), Verbal Verbs in the Noble Qur'an, Surat Al-Baqara, A deliberative study, $\mathrm{PhD}$ thesis in linguistics, Haji Lakhdar University, Batna, Algeria. 


\section{مطالعات روايت شُناس عرب؟}

شايا جايى: • H

كاربرد شناسى كَفتمان روايى قر آن و بلاغت استدلال واقناع؛

\section{بررسى موردى سوره هاى بقره و طه}

khadidjamerat@gmail.com

رايانامه:

خديجه مرات

گروه زبان و ادبيات عربى، دانشخاه محمد لامين دباغين، سطيف ك، الجزاير

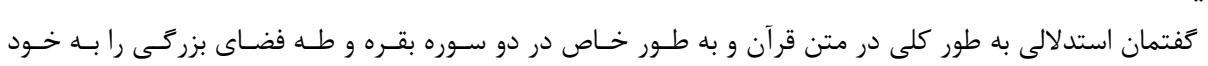

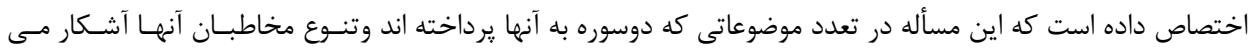

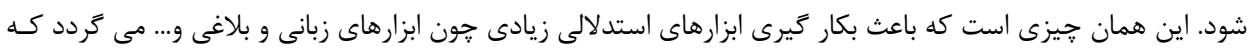

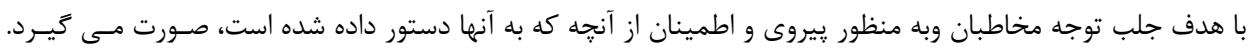

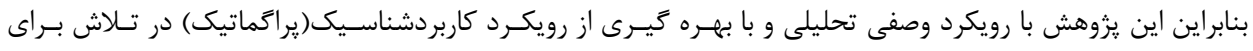

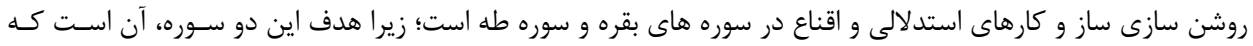

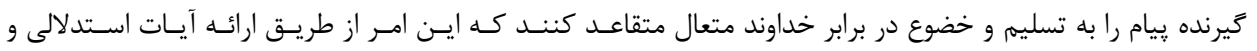

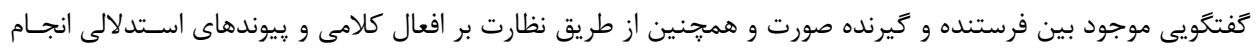

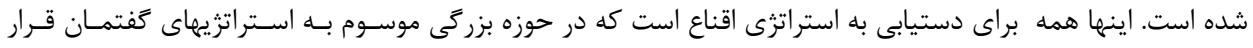

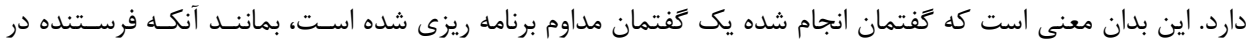

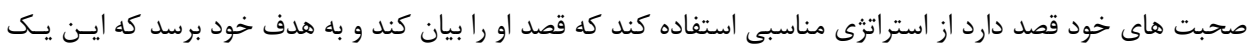

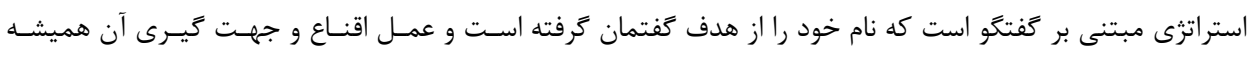

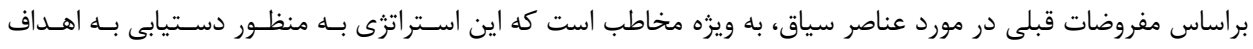

$$
\text { فرستنده استفاده مى شود. }
$$

كليد وازهها: استدلال، استراترى اقناع، كفتگكو، سياق وبافت متن، كفتمان، كاربردشناسى(يراگماتيسم)

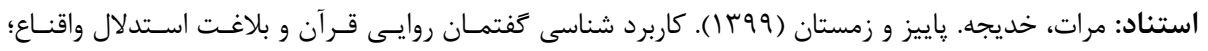

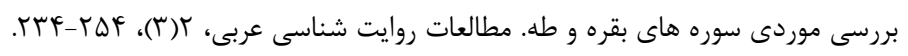

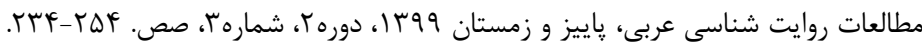

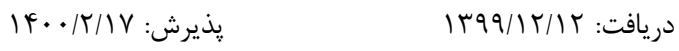

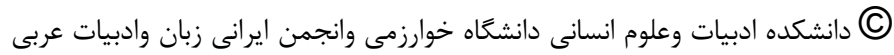

